\title{
Crisis Management and Consideration of Enterprises for the Production of Public Goods in Kosovo's Publication as a New State
}

\author{
PhD. Candidate, Driton Fetahu
}

European University of Tirana (UET), Republic of Albania

Copyright $\mathrm{C} 2019$ by authors, all rights reserved. Authors agree that this article remains permanently open access under the terms of the Creative Commons Attribution License 4.0 International License

\begin{abstract}
The process of the sanation of enterprises producing public goods represents a very complex, risky and expensive (politically, economically and business) venture. The long-lasting policy of treating the sector for production of public goods as an activity has its basic task to provide sheaply of gratis, the supplying of population and economy with public goods and services as well as exclusive political criteria in the choice of their management along with the non-selective subventions of various political, macroeconomic and business failures, developed an incremental conduct in practically each enterprise for the production of public goods regarding the changes in social, economic and technological surrounding. The start position in the present work is that it is necessary to raise the work efficiency of the enterprises for the production of public goods - by implementing the relevant techniques of crisis management with inner (internal) restructuring on the basis of individual programs made by respecting the methods and concepts of the following techniques: strategic planning and managing, team work, reengineering and benchmarking on one side and the specificities of restructuring these enterprises in societies and economies in transition and being reflected in undeveloped market infrastructure and absence of adequate regulatory public mechanisms for the substitution of the market mechanisms. This fact gives the certain degree of subjectivity to the whole process of the sanation of the enterprises producing public goods. According to this, the authors selected an approach where the basic task of the crisis management in this sanation of enterprises for the production of public goods in the adaptation of so-called soft elements (software) as (1) Changes in the structure of might between inner and outer factors with emphasis on making a precise, public and transparent framework for the public regulation of the conduct of enterprises running their business in the regime of natural or administrative monopoly, (2) Improvements in regulatory circles and rules of game for performing key business processes in the production and distribution of public goods, (3) Adaptation
\end{abstract}

of general frameworks defining the role and economic position of employees and (4) Development of the culture of organization (of the production of public goods) ensuring the quality of contents of characteristic rituals of the employees' behaviour in the function of more efficient satisfaction of the needs of customers or users of public goods and services.

Keywords Sanation of Enterprises for the Production of Public Goods, Crisis Management, Strategic Planning, Reengineering, Benchmarking, New Public Management

\section{Introduction}

The process of repairing a company for the production of public goods is a very complex, risky and expensive (political, economic and business) venture. Long-standing the policy of treating the sector for the production of public goods in Kosova as a business whose basic task is to provide cheap or free supplies population and economy by public goods and services, and exclusively political criteria in the choice of their management and non-selective system subsidizing various political, macroeconomic and business failures, they have developed incremental behavior, practically all, production companies public goods according to changes in social, economic and technological environment. In the light of radical changes in the socio-economic one the system of Kosova raises the question - Why are market mechanisms slow implemented in the domain of production of public goods?

According to the author, the key reasons for the dispute are inconsistent implementation of market mechanisms in the domain of production of public goods in Kosova are:

1. Encourage the political factor to fail in the implementation of the strategy structural adjustment of the real economy, renewal of the developmental 
drive on the basis for increasing employment and securing social security according to criteria of open market economy - partially compensated by providing special benefits around the entry (non-market) price of existential ones and infrastructure goods and services (which de facto has been granted the status of a public good - commercial products and services, such as: production, transmission and distribution of electric energy; import, transport, storage and distribution natural gas; water production; disposal and recycling of municipal, toxic and radioactive waste; and servicing financial liabilities for their own consumption.

2. In order to preserve the monopoly position of existing (pseudo) private or public enterprises (especially in the domain of production, transmission and distribution electricity and import, transport, storage and distribution of natural gas) - to large consumers, especially in the competitive sector, is practical their direct purchase from the manufacturer or from imports is disabled

3. Due to the blockade of the privatization of the development and interests of the broker-oriented entrepreneurial and political elites - building a large part of the infrastructure in the sector for the production of public goods or commercial goods, for example fixed telephony, local gas distribution infrastructure, cable television and the like is still almost exclusively financed from the ex-ante fees they pay potential consumers or from the budget at non-market prices

4. Due to the interest of various distribution-oriented coalitions - prices $i$ the method of participating in the cost of using one part of public goods, though for that there are appropriate conditions, not formed according to the economic one principles, while one part of the user is assigned (on irregular and non-transparent basis) the right to the inaccessible servicing of their own financial obligations for their production.

In line with the exposed, basic features of the crisis of the manufacturing company public goods in Kosova are: (1) Inability to efficiently implement projects expanded reproductions in line with changes in the structure and growth dynamics demand, (2) Inaccessible overvalue of all irrationality to users and consumers and (3) Inadequate protection of users and the public interest.

Obviously, to overcome the presented content of the cause $i$ the consequence of the crisis in the enterprise for the production of public goods is not enough standard remediation measures, which are reduced to financial consolidation, improvement of liquidity and (possibly) restructuring of the management. Also not full privatization as a means of overcoming the crisis at this time does not is a solution - due to underdevelopment of market infrastructure and low managerial capacity of a public factor in the organization of a transparent and efficient system of regulation of companies operating in the natural or natural state administrative monopoly.

In this context, to increase the efficiency of the production company public goods need measures to improve the external and internal management and control systems, restructuring of internal organizational structure, labor reduction, withdrawal from business activities that are can organize in the competitive sector, create the necessary base of capital for revitalization, modernization and new construction, in order to rationalize business and economy and quality of production of public goods raised to socially acceptable level.

The starting point in this paper is that it is necessary to increase efficiency work of enterprises for the production of public goods - implementation of appropriate ones crisis management technique for internal (internal) restructuring based on individual programs made by respecting methods and concepts the following techniques: strategic planning and management, team work, reengineering and benchmarking, on the one hand, and the specifics of restructuring of these companies in societies and economies in transition, which are reflected in the underdevelopment of market infrastructure and the absence of adequate public mechanisms regulation for the substitution of market mechanisms. Accordingly, they will be processed specificities related to the application of new public management techniques, strategic planning, reengineering and benchmarking in the context of needs remediation of enterprises for production of public goods in conditions unclear and inexplicably defined external incentives due to the absence of appropriate ones market mechanisms and low quality macroeconomic and political regulation for its substitution or replacement.

\section{Selection of the Model of Rehabilitation of the Company for Production Public Goods}

The choice of a model for remediation of a company for the production of public goods depends directly from goals to be achieved. As in all other cases - a successful strategy for remedying a company for the production of public goods must have short-term, mid-term and long-term aspect, of which the first is the most important to make its basic function was preserved - providing continuity in supply population, production and nonproductive spheres of concrete public good in scope that will not significantly jeopardize the living conditions and the conduct of business and others process. Precisely this criterion poses the greatest danger in structuring the goals of remediation of enterprises for the production of public goods, because short-term benefits from maintaining the production of public goods at any cost can cause multiple damages in the future. The danger of this approach is increasing as well 
because of the interest of the dominant political option to avoid any consequences in any way arising from the breakdown or sudden decline in the production of public goods. This indicates that the adoption and realization of short-term measures must be a part designed concepts of revitalization and new strategic orientation. In accordance with team, in establishing a balance between emergency and strategic in the process remedying the company for the production of public goods - the key role should be have the following activities:

- First, replace the existing one and create a new management - which would be loyal to the social mission of a company producing public goods, but who would be at the same time trained and interested in applying effective methods management in the process of using and securing the production factors necessary for production of public goods.

- Second, software cleansing for the production of public goods in the goal of withdrawal from secondary and tertiary business activities that are not are found in the natural monopoly regime, including the sale or redeployment of all capacities that exist parallel in the commercial (competitive) sector.

- Thirdly, the development of a new organizational structure with the following objectives: (1)

- creating conditions for approaching users of public goods in accordance with precision certain standards, (2) development of new models of cooperation with suppliers input inputs in the function of creating economically and technically more rational relationships dependence and reciprocity, and (3) the creation of new strategic coalitions, especially with private sector, as a means of managing development.

- Fourth, the development of a new ownership structure in the chain of reproduction public goods that will provide: (1) the development of corporate entrepreneurship as the basic generator of new business ideas and initiatives, (2) attracting a fresh one capital under the most favorable conditions for public finances and users; and (3) reduction of public expenditures for financing current business.

- $\quad$ Fifth, providing public support for remedying the crisis in production public goods. Namely, almost every form of rehabilitation, including privatization enterprises for the production of public goods (or a significant part of the process reproduction in the production of public goods) as a fixed asset for the long-term overcoming the crisis, that is, as a rule, higher prices for users and narrowing freedom of access to public goods. Therefore, rehabilitation activities must be transparent - for the public to be convinced of their worthiness. The foundation is Certainly any increase in the price of public goods due to privatization - must follow reducing fiscal pressures to current and future income.

In any case, choosing a model for remediation of production company public goods must be preceded by an exact analysis. In that sense, for real assessing the current position and initiating ideas for the choice of goals and mechanisms Rehabilitation can be applied to portfolio analysis. The basis for forming a portfolio matrix for the choice of the method of therapy for the production of public goods represents information on the key causes of the crisis (Table 1)

The basic problem in applying this approach is the need of a high level knowledge and reality in assessing your own resources, on the one hand, and impact the political factor and the need for concrete public goods, on the other hand. $\mathrm{U}$ in each case in the collection of information to create a portfolio of matrices for selection the method of therapy for the production of public goods must be included and an external factor, including the ultimate option - a complete release of the process providing appropriate information external specialized (consulting) company. Based on the assessment of these factors, it is formed appropriate portfolio matrix (Scheme No. 1).

As in any portfolio analysis and here there are situations in which it is it is necessary to take (forced) liquidation of the companies for the production of public goods. However, unlike the enterprise for the production of commercial goods, In this case, a public factor is well-known in the country, it has to prepare an alternative solution in the form of a program to establish a (new) public company, including a need ensuring the production of public goods in a transitional period, which must be what shorter because it is usually tied to the huge engagement of public finances.

Scheme no. 1 is Portfolio matrix - Deciding on the choice of the method of company therapy for the production of public goods. The general algorithm for remediation of enterprises for the production of public goods is presented in scheme no. 2. The rehabilitation process is divided into individual phases that are they consist of a complex of key tasks. 
Table 1. Overview of the necessary information for the diagnosis of the causes of the crisis enterprises for the production of public goods

\begin{tabular}{|ll|cl|}
\hline Internal causes (state of their own resources) & $\begin{array}{c}\text { External causes (influence of political factors and the state of } \\
\text { the public market goods) }\end{array}$ \\
\hline - & Management & - & Changes in socio-political system \\
- & Control system & Employment & Bargaining power according to political upgrade \\
- & Organizational structure & Changes in socioeconomic structure population \\
- & Participation of secondary and tertiary business activities & - Changes in production structure \\
- & The manufacturing process & Changes in non-productive structure \\
- & Process (channels) of distribution & & \\
- & & \\
- & Resality of the public good & & \\
\hline
\end{tabular}
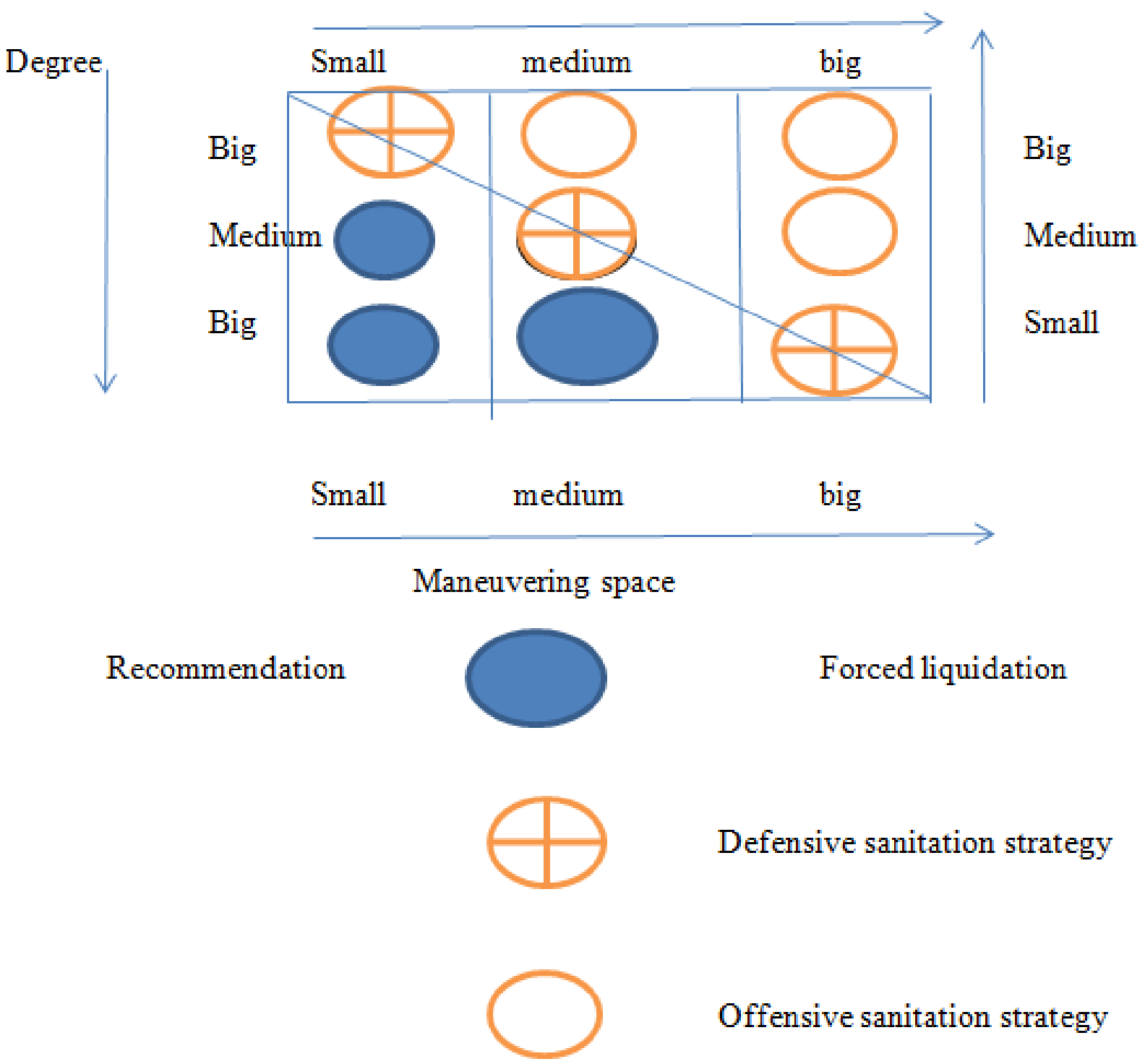

Figure 1. Neutraless painting 


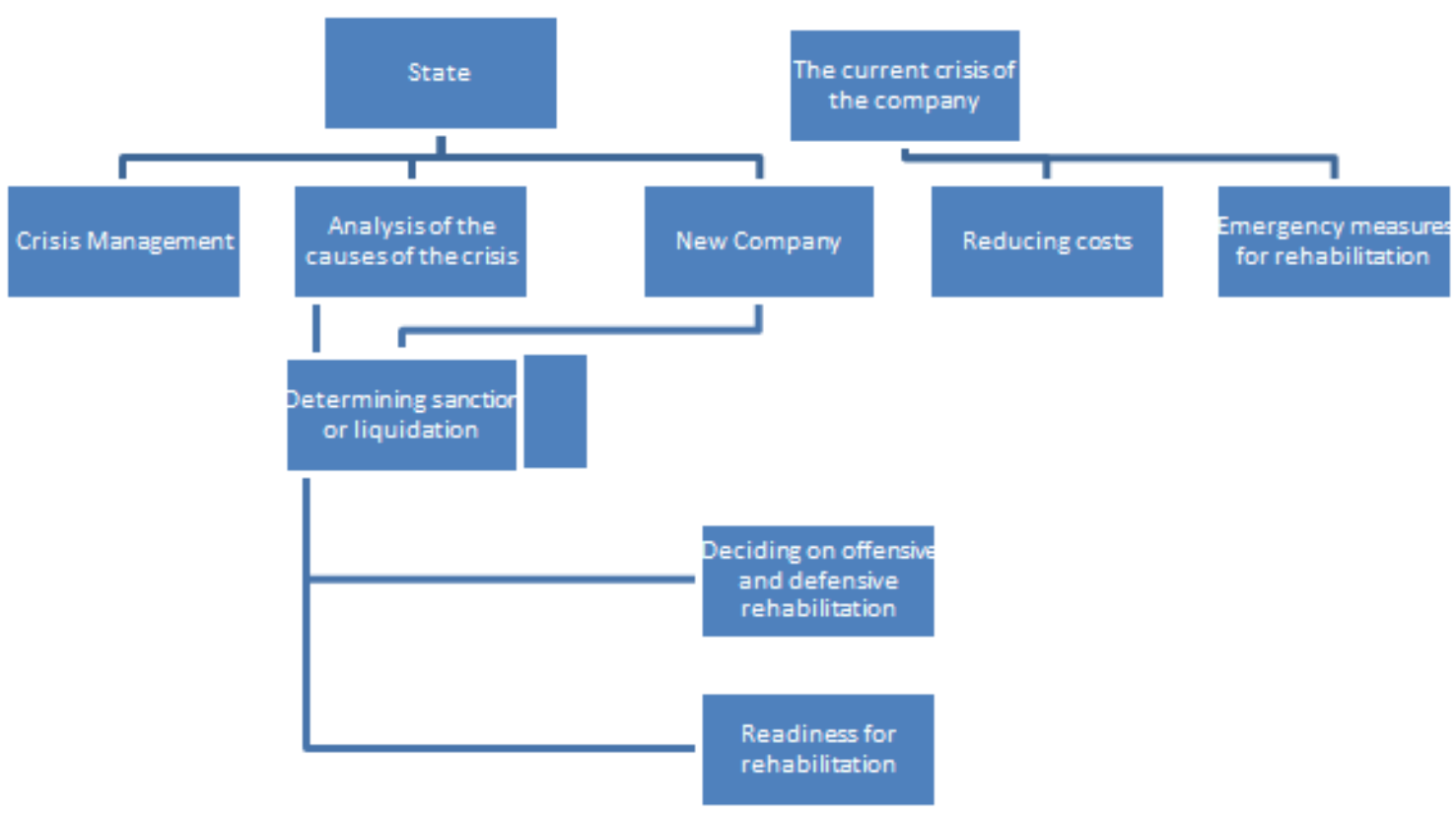

Figure 2. Scheme no. 2 Algorithm for remediation of enterprises for the production of public goods

The basic phases are: (1) Identifying the crisis in the production (concrete) of the public good, (2) Creation of crisis management that will in cooperation with the competent managers and consulting firms to undertake a rough analysis of the causes of the crisis, (3) Estimation of the weaknesses of the potentials of enterprises for the production of public goods with emphasizing the assessment of the ability of internal factors for rehabilitation, (4) Bringing urgent rehabilitation measures to ensure continuity in production of public goods and (5) detailed analysis and strategy formulation rehabilitation.

Because of the one-time, time-limited duration of each stock and the need to maintain continuity in the production of public goods, the implementation of the process rehabilitation should be carried out on a project basis. Obviously, coordination and monitoring of the remediation of enterprises for the production of public goods belongs to difficult management tasks. Because of the great public importance, the rehabilitation process enterprises for the production of public goods must be subject to preventive measures control to ensure timely identification of the impossibility achievement of certain goals or occurrence of delays in production of public goods and thus opened the process of activating the backup project - forced liquidation existing and establishment of a new company for the production of public goods.

\section{Role of Strategic Planning and Management in the Rehabilitation of the Crisis of the Enterprise for the Manufacture of Public Good}

Before analyzing the role of strategic planning and management in mastering crisis of enterprises for the production of public goods, it is necessary to precisely determine the role of planning in their business. Namely actual planning systems in these companies are mostly based on one-year plans in which are usually emphasized on financial aspects, especially in terms of the need to engage public funds to finance ongoing reproduction and investment. This approach is a reflection of the business concept of the company production of public goods as public services. This planning concept is by itself one of the main causes of the development crisis in manufacturing enterprises public goods. In order to overcome this situation, it is necessary for companies to production of public goods to adopt new concepts of business planning.

Namely, in the eighties of the last century in the market economy under the influence of dynamic and radical changes in the environment abandoned standard concept of business planning based on their division according to operating time (one-month and quarterly), short-term (one-year), medium-term (for a period of three to five years) and long term (with a period of five to fifteen years depending on the life cycle of a specific investment project) and a new one - based on the projected size of a particular business endeavor and assessment the consequence of the business decisions made. In line with the new concept of business planning, appropriate terms for their division were introduced: business forecasting, financial planning, one-year planning, long-term planning and strategic planning. The basic feature of this system is to individual types of business plans are formulated and realized autonomously at various levels of organization and to be based on some expectation that it brings the future. The development of concrete plans is mainly done on the project principles, and their mutual permeation and conflict 
are used as means for creating alternatives in making business decisions.

From the point of view of the need to remedy the crisis of the enterprise for the production of public goods special attention is drawn to the application of strategic planning techniques and management. The term itself signifies the process of making business decisions about it who will and what jobs will be performed or left and how the distribution will be done available resources between old and new business activities. Main goal These activities are designed to create a new enterprise configuration that will Have: (1) a sound financial structure, (2) qualified and dynamic management, (3) appropriate physical resources and personnel, (4) flexible organizational structure and (5) an efficient system of individual motivation, which cumulatively provide conditions for technically and economically efficient production quality goods that can be placed on selected segments of the global market in conditions of an open and harsh market game, that is, the flexibility that enables rapid reaction of the company to stochastic signals from the environment.

Since the company for the production of public goods is distinguished by its specificity which are reflected, above all, in a fixed program of basic production and distributions within a precisely defined market segment - into a practical one Applying strategic planning and management techniques requires some constraints based on a key premise - that development (companies for the production of public goods - the author's remark) must be based on principles thinning in terms of concentrating on basic activity and seeking socially and socially economically the most rational combinations of cooperation between public and private factors in the supply chain of inputs input, production and distribution (public goods - author's remark).

In this context, in the practical application of strategic planning techniques and management in the function of remedying the company for the production of public goods should use the following procedures:

1. Introducing a matrix organization based on the application of functional (management, development, business and production, logistics, personally) and economic (profit centers, cost centers) principles in the organization of internal ones business activities with the help of local businesses it was necessary to find the most appropriate way of engaging units that operate on the cost principle for a wider circle of companies producing public goods;

2. Technical improvements to existing technologies and processes in the goal improving the quality of public goods and rationalizing resource consumption - labor, raw materials and energy;

3. Introduction of operational and financial planning system in real time in order to shorten the cycle of production and distribution of public goods and the costs of their financing;
4. Developing a quality assurance system for processes and public goods; 5. Development of the motivation system in the function of reducing the costs of doing business, improving the quality of the process and public goods;

5. Reduction of physical resources (space, equipment and employment) at the basis of a comprehensive analysis of the level of capacity utilization and workers; 7. Withdrawal from secondary and tertiary business activities and their commercialization;

6. Restructuring of ownership in accordance with the aforementioned objectives: (a) development of corporate entrepreneurship as the main generator of new business ideas and initiatives, (b) attracting fresh capital under the most favorable conditions for public finances and users; and (c) reducing public expenditure on financing current business.

In accordance with this definition of the strategic planning structure and management in overcoming the crisis of enterprises for the production of public goods The basic task of crisis management is to adapt its so-called. Soft (software) elements, such as:

1. Changes in the power structures between internal and external factors with an emphasis on creating a precise, public and transparent framework for the public regulation of the behavior of a company operating in a natural or natural regime administrative monopoly.

2. Improvements in regulatory circuits and rules of the game to perform key business processes in the production and distribution of public goods.

3. Adaptation of the general framework for determining the role and economic position of employees.

4. Development of an organization's culture (production of public goods - remark author) to ensure the quality of the content of characteristic rituals behavior of employees in the function of more efficient satisfaction of the needs of consumers or users of public goods and services.

In line with this structure of activities - it is justified for the proposed configuration of strategic planning and management in the function of overcoming the crisis enterprises for the production of public goods use the term "reengineering", by which in this paper - the unity of activity in determining goals is defined restructuring of enterprises in order to adapt to business conditions in a turbulent environment and exploring the best ways for their realization (which represents strategic planning and management in the narrower technical sense!), s on the one hand, and the ways and processes for their practical realization (development politics!), on the other hand.

Before analyzing the role of reengineering in structuring goals and actions for overcoming the crisis of the enterprise for the production of public goods, it is necessary to consider its application on several levels. 
The first, initial and lowest level is definitely business reengineering, of which activities located within the enterprise and oriented towards rationalization and redesigning the process of production and distribution of public goods.

The second level is managerial reengineering, which marks the introduction new approaches in managing processes for the production and distribution of public goods.

The third level is mental or educational reengineering whose basic one function of education and change of attitudes of participants engaged in processes management, control, production and distribution of public goods.

On the fourth, the highest level is total reengineering, as a synthesis of all of the previous ones, and which, in addition to the reproductive whole, in whose frames it takes place the provision of inputs, the production and distribution of public goods includes and the institutional framework in which its external management is ensured and control (in this case, political system and management system, as well as economic and social policies for its operationalization).

\section{The Role of Reinzyinging in the Repair of the Company's Crisis Production of Public Goods}

In the analysis of the role of reengineering in the recovery of the enterprise production crisis public goods will be retained on the closer definition of two phenomena.

The first and crucial problem is determining the vision of the development of production and distribution of public goods. The vision, by definition, is the starting point of each reengineering activities. In order to achieve significant progress or modernization and the revitalization of the production and distribution of a particular public good, must be at Each of the above levels of the organization of reengineering has some vision $-\mathrm{u}$ form a clear, precise and public list of desires and goals for which it is achieved most of them advocate how they know and know, or how much they can. According to this knowledge, it is easy to compile the current list of problems which need to be overcome in the production of public goods.

At this site, we will only list those that are relevant to the institutional framework in which its external management is ensured and control (i.e. in the framework of total reengineering): (1) How to provide balance in public finances and reduce the share of public spending in the social sector product? (2) How to proceed more effectively with the revitalization process and modernization of infrastructure for the production and distribution of public goods? (3) How to implement and complete the process of privatization and transformation of ownership in production and distribution of public goods? (4) How to Improve Management and Rationality of the functioning of the public sector? (5) How to attract private capital and know how? (6) How to get and use international assistance? (7) How launch a new development cycle needed for revitalization and modernization production and distribution of public goods?

This is a certain problem of building a (developmental) vision of production and nobody is concerned about the distribution of public goods. Current political elite on the authorities (and also in the opposition) have mixed strategy, tactics and daily activities in public regulation of the production of public goods, and it became completely unclear what it should have been done. In the absence of a (developmental) vision, many elements of reality in production and distribution of public goods seem to be sty-hearted, frivolous, wrong and hasty.

The second is an overview of how to organize the reengineering actor. Actors reengineering in the production and distribution of public goods in accordance with their functions will be divided into three basic groups:

1. The Management Committee - should define the content of the strategy reengineering and provide supervision in its implementation. Basic tasks of the Committee for management are: determining concrete processes in production and distribution public goods that should be radically redesigned, launching initiatives for its redesigning and providing support for its redesign.

2. The reengineering team - should be composed of at least five up to ten people in charge of the realization of the reengineering of a particular process production or distortion of a particular public good.

3. The basic task of the team is to determine the meaning of the rules governing the process in the desired way. In order to avoided subjectivity in determining the rules in the center of the process should be put the output by determining the specific users and the degree of adequacy and quality levels public goods or ancillary services to be provided.

The level of quality is determined by the analysis of good practice in the world and attempts to base on this, its own standards of functioning are appropriate economic possibilities of users. In any case, the process that takes place subjected to redesigning must be viewed with the eyes of the users of the public good.

Team members for the implementation of reengineering should be selected based on criteria, to every two to three internal members (from the process that is the subject redesigning) should be an external member - whose basic task is to provide objectivity and different views on the process being subjected redesigning. The reengineering team should manage itself and have it great autonomy in work, while his work must be based on free communication, consensus and fostering innovation. In any case, the leader Team reengineering should behave as the first among equal the ethical code of innovation.

By defining that politics must be a servant of the 
profession and knowledge, and not the other way around, as it is our current practice.

1. The re-engineering manager is the coordinator of the production process or distribution of the public property subject to redesigning. Team Leader for Reengineering may or may not be a reengineering manager of a specific one process. In fact, practice has shown that it is the reengineering leader. It is best to choose the natural leaders who have expressed themselves within the team for re-engineering because they are usually able to motivate other actors to change.

This is a strategy for the reengineering of the production company public goods and its macroeconomic and institutional environment are explicitly relies on the achievements of benchmarking.

\section{Benchmarking and Sanitation of the Crisis Company for Production of Public Goods}

Benchmarking is a technique for: (1) Detailed analysis of all characteristic shapes processes and their performance within the enterprise, (2) Measurement of adequacy implementation of the process, (3) Comparison of ways of realization of the process and their effect in relation to the best (world) companies in the business, and possibly with the best (world) enterprises in other activities; and (4)
Improvement processes and their effect to the level of the best (world) enterprises in the business, that is, the best (world) companies in other activities. Main goal The application of benchmarking techniques is based on learning on your own and others mistakes and experiences set up the appropriate system of internal standards that provides an exact estimate of how much the company (really) is doing well and how much is the size of the gap in relation to other enterprises. Accordingly, the technique benchmarking plays a key role in determining the final goals of the recovery crisis enterprises for production of public goods and measurement of achieved results in intermediate. Basic methodological framework for the application of benchmarking techniques for the rehabilitation of the company for the production of public goods is given in scheme no. 3. The presented methodology indicates that modeling of actions on realization improvements in order to overcome the crisis in the enterprise for the production of public goods do not make sense, if there are not at least implicitly defined: (1) Standards for comparison, (2) Cost estimate and (3) Estimating the timing of the achievement of objectives, to which they must join and their common dimensions, such as: (4) Relationship between parts and the whole, (5) The problem of quantification and measurement of costs the influence of individual factors on the basis of their individual and common and (6) Risk assessment related to radical decision making the transformation of the internal organization in conditions unclear and imprecise defined macroeconomic and institutional environment.

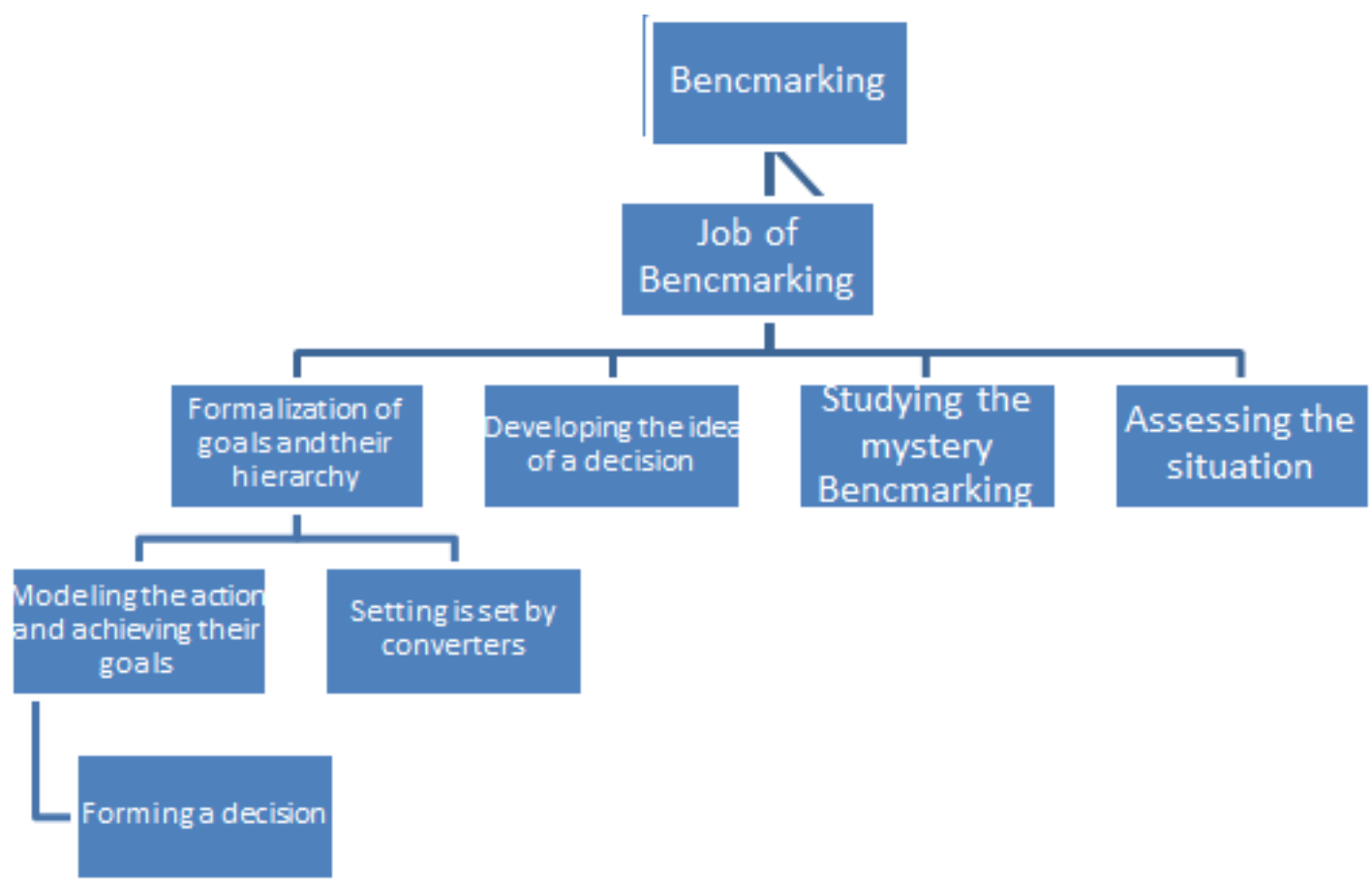

Figure 3. Scheme no. 3 Methodological framework for the application of benchmarking techniques in rehabilitation enterprises for the production of public goods 
Authors in accordance with the structure of the problem, suggest the operationalization of these techniques by dividing activities into three groups that should be implemented in parallel and simultaneously. The first includes activities to unburden the organization in order to leave rigid hierarchical organizations characteristic of manufacturing company's public goods - in order to create a flexible organizational structure with a workplace teams and centers of power in the function of satisfying users of public goods, such as the main actors of the organizational structure.

The second involves the establishment of a new model of the game that will provide the functioning of a company for the production of public goods - as a community of people which works together in order to ensure high income exclusively based on satisfying users of public goods and not overturning or misusing the public finance.

Third, it includes the formation of temporary (project) work teams for realization of benchmarking in five basic groups - which should perform activities defining, analyzing and measuring: (a) the structure of the distribution of power between the enterprise and political system and management system for public regulation of its behavior, (b) the power distribution structures within the enterprise for the production of public goods, (c) the specific content of the regulatory circles and the rules of the game to perform the key the production and distribution of public goods, (d) the general framework for which they are determines the role and economic position of employees, and (e) specific elements of culture organizations, which determine the quality of the content of characteristic rituals employees, in order to be based on the process of meeting the criteria for meeting the needs users, they saw how to introduce improvements, as well as the way and the location of their introduction. Problem with this particular content of the application of the benchmarking technique in the resolution of the crisis of the enterprise for the production of public goods is the majority internal and external actors think that it is impossible to achieve everything unachievable, which leads to the essence of the methodological definition of the term crisis management, and that is its definition in the sense of the so-called "New public management". In the meaning used in this paper "new public management" means a mix formed from the theoretical achievements of the constitutional economy and using the theory and practice of business management in the production domain and distribution of public goods. The basic implications of this particular content "New public management" in the field of crisis management review the rehabilitation of enterprises for the production of public goods are as follows: (1) introduction the principle of contract management in the practice of managing the company's remediation the production of public goods, (2) the application or simulation of a market mechanism in securing public goods; and (3) linking the incomes earned on management and control in the process of remediation of enterprises for the production of public goods with the results of their work and business improvement.

The basic requirement for the implementation of the concept of "new public management" in Rehabilitation of enterprises for the production of public goods is, above all, intelligent social thinking and actions that will be recognized most rationally an economic solution for every social or economic phenomenon individually and which will be acceptable to all interested actors. This in the first place, depends on will, knowledge and strength of "human capital" engaged in the political sphere and public sector to accept entrepreneurship and creativity as basic elements of its functioning. Accordingly, the Intelligent Public Thinking Base and action in this sphere is certainly a public and private sector partnership in providing public goods. Not entering this place in its content we will indicate that for the application of this technique it is necessary to ensure: (1) strong and lasting Sustainable political support at the level at which a specific enterprise operates production and distribution of public goods, (2) flexible legislation, and (3) direct customer support in creating conditions for financial sustainability project.

\section{Conclusions}

First, the dominance of the political factor and the urgent of the essential, as well as the understanding remediation as a set of financial measures for securing liquidity and minimum operational readiness based on a simplified relationship on a relation: enterprise for the production of public goods - the organs of executive power, have caused permanent ones negative effects from the aspect of their basic target function and strategic orientation in the development of core business. Obvious use of various types subsidy for crisis management and political voluntarism in the choice of management are stimulate enterprises to produce public goods - to deal with themselves, a not users of public goods with all the repercussions on incentives regulation of companies operating in the natural or administrative regime monopoly. Therefore, by engaging a private factor, you should start with more flexible forms of partnership between the public and private sectors, and especially with by withdrawing a company for the production of public goods from all activities that are I can organize in the competitive sector.

Thirdly, to increase the efficiency of the production and distribution enterprises public goods are necessary measures for: (1) improvement of external and internal ones management and control systems, (2) restructuring of internal organizational structures, (3) labor reductions, (4) withdrawal from business activities that can be organized in the competitive sector and (5) create the necessary database capital for revitalization, modernization and new construction - to be streamlined business and economy and 
quality of production and distribution public goods were raised to a socially acceptable level. Fourthly, in order to increase the efficiency of the production enterprises and distribution of public goods - it is necessary to perform internal (internal) restructuring based on individual rehabilitation programs - made By considering methods and concepts of techniques: (1) strategic planning and management, (2) team work, (3) reengineering and (4) benchmarking, on the one hand and the specificity of the restructuring of these companies in societies and economies in transition, which are reflected in the underdevelopment of market infrastructure and absence adequate public regulation mechanisms for the substitution of market mechanisms. This gives the whole process of remediation of the company for the production of public goods a certain degree of subjectivity.

Fifth, the basic task of crisis management in the rehabilitation of the company for production and distribution of public goods - is the realization of the program for adapting his so-called. soft (software) elements, such as: (1) changes in the power structures between internal and external factors with with an emphasis on creating a precise, public and transparent framework for the public regulation of the behavior of a company operating in a natural or natural regime administrative monopoly mechanisms only; (2) improvements in regulatory circles and rules of the game to perform key business processes in production and distribution of public goods; (3) adapting the general framework to be determined role and economic position of employees; and (4) the development of the organization's culture (production of public goods - author's remark) in order to ensure quality content of characteristic rituals of employees' behavior in a more efficient manner satisfying the needs of consumers or users of public goods.

The growth of public spending, fiscal pressures, invisible and visible public debt, cost inflation and disorientation in development (first of all, inclusion activities that can be organized more effectively in the competitive sector), a ultimately, a negative attitude towards social, technological, and economic changes in the environment.

Secondly, to overcome the crisis in the production of public goods there are not enough standard remediation measures - which are reduced to financial consolidation, liquidity improvement and (possibly) restructuring management. There is also no complete privatization as a means of overcoming crisis of enterprises for the production and distribution of public goods does not present solution - due to underdevelopment of market infrastructure and low management the ability of the public factor to organize a transparent and efficient system.

\section{REFERENCES}

[1] Vendosja Afariste, Ibrahim Kuka, Prishtinë

[2] Adžić, S., Benčmarking i prestruktuiranje preduzeća, "Menadžment totalnim kvalitetom" Yu ISSN 0354-9771 No 2, Vol 27, (1999), str. 5-9, Jugoslovensko udruženje za standardizaciju i kvalitet, Beograd, 2002.

[3] Bailey, S., Public Sector Economics: Theory, Policy and Practice, Palgrave, 2002.

[4] Beer, S., Diagnosing the System of Organiyations, Chichester, 1985.

[5] Bendell, T, Boulter, L. and Gatford, K., The Benchmarking workout, Pitman Publishing, 1997.

[6] Camp, R. C., Bussines Process Benchmarking, ACQS, 1995.

[7] Hammer, M. and Champy, I., Reengineering the Corporation, Harper Business, New York, 1993.

[8] Osborn, D., and Gaebler, E., Reinventing Government, 1992.

[9] Shaub, M., European Regional Policy, Verlag Ruegger, 2000.

[10] Stiglic, E. J., Ekonomija javnog sektora, Ekonomski fakultet, Beograd, 2004.

[11] Studija, Covernment of the Future, OECD/PUMA, 2000

[12] Trothman - Dickenson, D. I., Economics of the Public Sector, Macmillan Press Ltd, 1996. 